\title{
МИРОВАЯ ПОЛИТИКА
}

Вертяев К.В.

DOI: 10.7256/2305-560X.2016.4.21357

\section{ОБОСТРЕНИЕ ТУРЕЦКО-КУРДСКОГО МЕЖЭТНИЧЕСКОГО КОНФЛИКТА В ТУРЦИИ (в 2015-2016 гг.)}

\begin{abstract}
Аннотация. ВОбъектом изучения статьи являются обострившиеся турецко-курдские отношения в Турции в период проведения внеочередных парламентских выборов в стране в ноябре 2015 года и военной интервенции Турции на территорию Сирии в 2016 году, происходившей на фоне становления курдской автономии в Сирии. Учитывая актуальность указанной темы, за основу анализа брались те события, которые явились непосредственным катализатором обострения межэтнического конфликта в стране и активизации боевиков из Партии рабочих Курдистана (ПРК), поддерживаемых в Турции легальной про-курдской Партией демократии народов (ПДН), выступающей за автономизацию курдских регионов Турции, расширение прав и свобод национальных меньшинств. Изучение темы произведено в форме анализа основных событий в указанный период на основе данных, полученных из турецких, отечественных и международных средств массовой информации. В статье вскрыты закономерности внутриполитических процессов в Турции и их внешнее проявление в участии турции в сирийском кризисе, дан анализ современного состояния курдской проблемы, ее актуализации на фоне сирийского кризиса, интересах Турции в регионе, а также роли курдских политических элит во внутренней жизни страны.
\end{abstract}

Ключевые слова: Турция, курды, Партия рабочих Курдистана, курдские партии, сепаратизм, война в Сирии, курды Сирии, Демирташ, Оджалан, конфликт.

Abstract. The research object is the aggravation of Turkish-Kurdish relations during the snap parliamentary election in November 2015 and the Turkish military intervention in Syria in 2016 in the context of the establishment of the Kurdish autonomy in Syria. Taking into consideration the importance of this problem, the author analyzes the events, which acted as an indirect catalyst of the escalation of the interethnic conflict in the country and the activation of combatants from the Kurdistan Workers' Party (PKK), supported by the legal pro-Kurdish Peoples' Democracy Party of Turkey, advocating for the autonomy of Kurdish regions of Turkey and the extension of rights and liberties of national minorities. The research is based on the analysis of the key events of the mentioned period on the base of the data, acquired from the Turkish, Russian and international mass media. The article reveals the patterns of domestic policy processes in Turkey and their manifestation in Turkey's participation in the Syrian crisis. The author analyzes the present state of the Kurdish question, its intensification in the context of the Syrian crisis, Turkey's interests in the region and the role of the Kurdish political elites in the country's domestic politics.

Key words: Turkey, Kurds, the Kurdistan Workers' Party, the Kurdish parties, separatism, war in Syria, the Syrian Kurds, Selahattin Demirtas, conflict.

П роисходящая с августа 2016 года интервенция вооруженных сил Турции на территорию северной Сирии вызывает осуждение со стороны многих националистически настроенных курдов по обе стороны турецко-сирийской границы. Объявленное в марте 2013 года перемирие между курдскими повстанцами, сторонниками находящегося в турецкой тюрьме лидера партии рабочих Курдистана (ПРК) Абдуллы Оджалана, и турецким государством было прервано самоподрывом исламиста летом 2015 г. в Суруче, в результате чего погибли 32 курдских активиста. Это явилось предполагаемым актом мести за военные неудачи вооруженных сил сторонников ИГИЛ (запрещенного в РФ), на фоне победы вооруженных сил сирийских курдов города Кобани и успешно- го их военного противодействия при поддержке иракских пешмерга силам т.н. «исламского государства». Сторонники ПРК видят взрыв в Суруче направленный против курдов непреднамеренный результат мало афишируемой поддержки Эрдоганом радикальных суннитских исламистов из ИГИЛ, во всяком случае, до объявления их в Турции террористической организацией.

После теракта в Суруче курдские радикалы из Партии рабочих Курдистана (ПРК) обвинили Турцию в пособничестве исламскому радикальному терроризму. В оппозиционных изданиях страны появились материалы, разоблачающие теневые схемы поставок вооружений боевикам ИГИЛ. На этом фоне резко обострилась обстановка на юго-востоке Турции: последовал целый 
ряд столкновений, в которых погибли двое полицейских, что радикальными «ястребами» из числа сторонников ПРК было объявлено, как акт мести за трагедию в Суруче. Сразу после убийства полицейских в Турции последовали рейды, в ходе которых были задержаны как сторонники ИГИЛ, так и сторонники ПРК. Ответные действия турецкого государства не заставили себя ждать: была произведена серия ракетных ударов с воздуха и земли по позициям курдских повстанцев из ПРК в Кандильских горах Ирака. При этом стоит помнить, что начиная с 1992 года такие удары по их лагерям, а также рейды турецкой армии на территорию сопредельного Ирака происходили довольно регулярно.

Волна насилия охватила и Турцию: в реультате серии терактов со стороны таких террористических группировок, как «Ястребы освобождения Курдистана» в Анкаре и Стамбуле, направленных против турецких полицейских и военнослужащих погибли около сотни человек. Это стало симптомом возрождения серьезного межэтнического конфликта в Турции, в заложники которого превратилась прошедшая в начале июня в парламент Турции про-курдская Партия демократии народов (ПДН). Эта партия была создана в 2013 г. и объединяет не столько националистически настроенных курдов, сколько весь спектр представителей левого движения страны. Считается, что партия «курдских социал-демократов» была создана по прямому распоряжению находящегося в тюрьме лидера ПРК Абдуллы Оджалана для того, чтобы в период предвыборной агитации дистанцироваться от курдского этнического партикуляризма и создать широкую политическую платформу для левого движения Турции [1].

В негласном переговорном процессе турецкого государства с лидером курдских повстанцев Оджаланом до недавнего времени ключевой оставалась тема о том, должны ли курдские партизаны, действующие на территории Турции сложить оружие и вернуться к нормальной жизни. Дело в том, что ПРК рассматривает военизированные силы своих инсургентов на территории Турции в качестве возможной основы сил правопорядка в будущей курдской автономии в Турции, на что турецкое государство никогда не согласится. Так, нынешний со-председатель ПДН Салахаттин Демирташ считает, что ПРК имеет право сохранить свою мобилизационную структуру и быть задействованной в условиях чрезвычайных ситуаций в регионе, в качестве отрядов гражданской обороны [2, с.258]. Таким образом, в период перемирия судьба вооруженных формирований ПРК являлась основным камнем преткновения на пути политического урегулирования курдской проблемы Турции.
Однако после попытки госпереворота в Турции в июле 2016 г, давление на курдских националистов (кстати, не поддержавших заговорщиков) только усилилось. Противодействие Турции вооруженным вылазкам курдских повстанцев на турецкую территорию выражается, в том числе, и в установлении добрососедских отношений между нынешним политическим режимом Турции и руководством Иракского Курдистана. Турция дает понять, что, скорее всего, не будет препятствовать возможному провозглашению независимого Курдистана на территории северного Ирака в обмен на взаимопризнание нерушимости границ между Курдистаном и Турцией. Это может означать также и попытку провоцировать региональное правительство курдов в Эрбиле на военные действия против баз сторонников ПРК на территории Кандильских гор. При этом и Иран, и Барзани отказываются проводить какую-либо совместную военную кампанию против лагерей апочистов в Кандильских горах на территории Иракского Курдистана. Негативно к идее проведения Турцией наземных операций против баз апочистов в Северном Ираке отнеслись и Соединенные Штаты. В результате геополитические и внутренние реалии предполагают политическое решение в виде разоружения и политической легализации ПРК в Турции, однако турецкое государство никогда на это не согласится.

Вооруженная тактика, до сих пор используемая в противостоянии ПРК и Турции, а также радикальная политическая риторика с обеих сторон иногда создает обманчивое впечатление, что ничего особенного не изменилось в течение последних двадцати лет. Соответственно, ПРК по прежнему считается в Турции террористической организацией, а курдским националистам в Турции, как показали последние события с задержаниями депутатов от ПДН, могут запретить заниматься политикой по причине нанесение ущерба единству страны. С другой стороны, нельзя не заметить, что Анкара, раньше используя жесткий силовой подход в отношении курдского повстанческого движения, ныне репрессиям подвергает лишь насильственные, военные атаки ПРК, а не подстрекательство к противоправным действиям. Нынешняя официальная позиция Турции заключается в том, что курдский вопрос необходимо решать в рамках обеспечения прав человека, с уважением общечеловеческих ценностей.

Объявленное в марте 2013 года перемирие сулило надежды на исключительно мирный диалог между турецкими властями и подконтрольными Оджалану курдами, но оно было прервано. С возобновлением вооруженных действий Оджалан из тюрьмы, и лидер прокурдской Партии демократии народов (ПДН) Салахаттин Демирташ потребова- 
ли незамедлительно восстановить перемирие. По мнению ведущих функционеров ПДН, эскалация насилия была выгодна президенту Эрдогану, который всеми силами стремился к тому, чтобы провести новые досрочные выборы и получить управляемое большинство в парламенте. [3].

На этом фоне в Турции заметно растет политическое влияние С. Демирташа, как лидера, выражающего интересы курдского этнического меньшинства. Стоит напомнить, что он был одним из кандидатов на пост президента страны, но, естественно, не смог конкурировать по популярности с Эрдоганом. Как со-председатель ПДН, С. Демирташ имеет политический авторитет не только в Турции, но и в Европе. Скорее всего, снятие с него депутатских полномочий в мае и арест в конце 2016 года только добавили ему популярности среди оппозиционных президенту Эрдогану политических сил Турции - в основном, левого толка.

Вторым немаловажным аспектом, осложнившим курдский вопрос в Турции за последние два года, стала гражданская война в Сирии. Поток беженцев оттуда в Турцию возрос - их расселили в основном на юго-востоке страны, в местах проживания курдов. По мнению ряда функционеров ПДН, правительством Турции некоторое время назад рассматривался вопрос предоставления турецкого гражданства сирийским беженцам (в основном, арабам), и их расселение в регионе компактного проживания курдов, в частности, в Кахраманмараше имело целью нивелировать этнический партикуляризм указанных регионов.

Вторым «сирийским» аспектом курдского фактора в Турции является становление курдской автономии на севере Сирии (с марта 2016 г. Федерации Северной Сирии), которая в Турции рассматривается как плацдарм апочистов (т.е. сторонников Абдуллы Оджалана). Ведущую политическую и военную роль в курдской автономии Сирии играет Партия демократического союза (ПДС), фактически аффилированная с Партией рабочих Курдистана, запрещенной в Турции.

При этом прямое военное вмешательство Турции в сирийские дела не может не беспокоить режим Асада, поскольку Турция в этом случае будет опираться на сирийские военно-политические силы, оппозиционные нынешнему сирийскому руководству. На этом фоне у Турции есть серьезные опасения, что Асад возобновит свое давнее сотрудничество с курдскими сепаратистами в Турции, учитывая традиционно тесные связи Сирии с оппозиционно настроенным к Турции курдским политическом движением еще со времен Асадастаршего.

С первого взгляда может показаться, что синхронность войны Эрдогана одновременно и с ПРК и с запрещенной в РФ ИГИЛ являются очевидным месседжем турецкого президента: Турция не будет делать различий между ИГИЛ и ПРК, считая и тех и других террористами и угрозой национальной безопасности страны. Однако фоном этих событий стали непреодолимые сложности создания коалиционного правительства в Турции после очередных выборов в июне 2015 г. Получившая около 13\% голосов про-курдская Партия демократии народов (ПДН), по словам ее лидера С. Демирташа, на стадии формирования правительства «оказалась выброшена за борт политического процесса Турции» [3]. Опять же, по словам Демирташа, ПРК уже 20 лет как отказалась от курса на отделение от Турции, взамен предложив концепцию «демократического конфедерализма», как формы самоопределения курдов Турции и, возможно, и сопредельной Сирии, где сильно влияние аффилированной с ПРК Партии демократического союза [3]. Однако это вызывает опасения турецких элит, что подобный проект станет началом создания «Большого Курдистана».

Прохождение в парламент Турции прокурдской оппозиционной партии сыграло ключевую роль в том, что сторонники правящей Партии справедливости и развития фактически лишались управляемого большинства в парламенте. Внесение изменений в конституцию и переход к президентской форме правления позволил бы контролировать парламент, который со всей очевидностью становился для президента трудноуправляемым, однако с нынешним составом парламента это сделать будет трудно. Серия переговоров о конституционной реформе дала понять, что Партия демократии народов не против президентской формы правления, но выступает против действий конкретного президента - Реджепа Эрдогана. Однако законодательное закрепление президентской формы правления в Турции, по мнению депутата от ПДРН Алтана Тана, должна подразумевать изменение 42 и 66 статей конституции страны, в которых провозглашается, что все граждане страны являются турками.

Согласно своему нынешнему уставу Партия демократии народов (ПДН) определяется, как партия левого, социал-демократического толка объединяющая различные политические группы и меньшинства (этнические, политические, религиозные, представителей рабочего класса), которые намереваются политическим путем добиваться как признания своих прав, так и уважения прав человека, а также участия в политическом управлении страной. Краеугольным камнем в программе остается право на использование родного языка, в том числе и в образовательной сфере, а также обеспечение прав трудящихся, рав- 
ноправия женщин, беженцев, секс-меньшинств итд. По словам со-председателя ПДН, «избиратели оказали поддержку его партии не потому, что она представляет интересы курдов, а в силу того, что пришло время для формирования сильной альтернативы политическим партиям, основанным на национализме и нео-национализме» [4].

В январе 2015 г. сторонники партии заявили, что пойдут на выборы от ПДН, а не как независимые кандидаты. Однако убежденность ПДН в необходимости идти на парламентские выборы окрепла после того, как ее со-председатель Салахаттин Демирташ получил 9,8\% голосов на президентских выборах в августе 2014 г. За весь период агитационной кампании представители ПДН заявляли, что их беспокоят не только проблемы защиты культурных прав курдов. ПДН позиционировалась, как партия, открытая для представителей разных народов и конфессий, населяющих Турцию. Победа прокурдских сил обозначила важные политические изменения, имеющие долгосрочные последствия, которые выражаются в корректирующем воздействии на политические процессы в стране. Касается это и политики Турции в отношении Сирии, где сформировавшаяся на севере страны курдская автономия видит в турецкой ПДН своего главного союзника на международной арене. Целью ПДН, по словам С. Демирташа, являлось увеличение своего успеха и обеспечение до $20 \%$ голосов избирателей, подразумевая, что ей удастся аккумулировать вокруг себя протестный по отношению к Эрдогану электорат [4].

Однако в самой Турции формирование правительства не произошло в отведенное время, и президентом на 1 ноября 2015 г. были назначены перевыборы, политическим бэкграундом которых стало явно обострившееся курдо-турецкое противостояние, что не могло не сказаться на уменьшении популярности как ПСР, так и прокурдской ПДН в Турции. По словам Ибрагима Айхана, одного из турецких депутатов от ПДН, Эрдогану перед внеочередными выборами в ноябре 2015 г. было выгодно состояние хаоса, в котором будет невозможно сформировать устойчивое правительство, что позволило бы убедить избирателей, что только его партия, обладающая большинством в парламенте, будет способна эффективно управлять страной на фоне резкого обострения межэтнических отношений в Турции [5]. В самой Турции обострение конфликта выразилось в арестах и задержаниях сторонников ПДН. Многие расценивают это, как запугивание курдов перспективам возвращения во времена девяностых, когда здесь шла настоящая гражданская война. Турецкая сторона увидела в убийствах полицейских сигнал возобновления войны со стороны ПРК, которая за время шаткого перемирия акку- мулировала свои силы, заручаясь международной поддержкой в противостоянии с ИГИЛ.

На таком фоне в ноябре 2015 г. состоялись внеочередные парламентские выборы в Турции. Несмотря на активное противодействие турецких националистов, представители курдов прошли в парламент страны, получив около 11 \% голосов избирателей [4]. Турецких курдов поздравил с прохождением в парламент президент Иракского Курдистана Масуд Барзани. Для Барзани эта победа очень важна в свете возможной курдской независимости в Ираке, к которой недвусмысленно стремятся все политические элиты иракских курдов, старающиеся заручиться в этом вопросе поддержкой ближневосточных государств и самой Турции. Для Барзани прохождение курдов в парламент Турции видится очень важным, поскольку традиционные националистические элиты Турции в лице Партии националистического действия (ПНД) или Народно-республиканской партии (НРП) крайне негативно относятся к идее независимого Курдистана у себя под боком, считая прежний Мосульский вилайет своей исконной территорией, несправедливо отторгнутый у молодой Турецкой республики в 1926 году, а также опасаясь того, что такое новое государственное образование станет «центром притяжения» для собственных курдов в их стремлении к независимости [6, с.168]

Необходимость вовлечения курдской оппозиции в сферу легальной политики диктовалась желанием минимизировать риски неконвенциальных акций протеста на юго-востоке страны и поддерживать хрупкое перемирие между правительством и Партией рабочих Курдистана, достигнутое в марте 2013 года. Однако после снятия в мае 2016 г. иммунитета с депутатов парламента, представляющих курдскую оппозицию, и массовых арестов функционеров из ПДН по обвинениям в сепаратизме в октябре 2016 г. вести такие переговоры для националистически настроенных курдов становится все труднее.

Важным фоном здесь является активное становление курдской квазигосударственности в северных приграничных с Турцией районах Сирии. Однако для Турции курдская автономия («республика Рожава») на севере Сирии представляется плацдармом дальнейшего создания курдского государства, поэтому для Анкары ПРК, с точки зрения ее геополитических интересов, является более опасным военным фактором, чем ИГИЛ.

Второй немаловажной причиной обострения турецко-курдских отношений является то, что успехи сирийских курдов были также опосредованы российскими и американскими авиаударами по позициям ИГИЛ. США стоят перед сложной дилеммой не навредить американо-курдским от- 
ношениям: курдские вооруженные формирования в Сирии видятся наиболее эффективными наземными силами, ведущими борьбу с ИГИЛ. Однако, существование де-факто независимых курдских территорий и их дальнейшая легитимация в глазах мировой общественности в форме национально-освободительной борьбы сирийских курдов не может не беспокоить Анкару, которая при поддержке США стремится создать бесполетную зону над частью курдских территорий в Сирии, непосредственно примыкающими к турецкого границе. При этом Партия демократического союза в Сирии и ПРК в Турции являются союзниками, если не сказать - одной военно-политической силой.

Так, в августе 2016 года при поддержке американской авиации силы курдской самообороны освободили от ИГИЛ город Манбидж, расположенный западнее реки Евфрат. Однако начало военной интервенции Турции в Сирию, а по сути, на территорию Сирийского Курдистана для многих националистически настроенных курдов Турции является фактором, мобилизирующим их протестный потенциал. С точки зрения националистически настроенных курдов, вторжение турецких войск на территорию Федерации Северной Сирии (ФСС) может рассматриваться, как прямое посягательство на их суверенитет, что может привести к тому, что ПРК перенесет свою вооруженную активность на территорию Сирии для противодействия интервенции Турции и в отстаивании курдского суверенитета.

Параллельно с военной интервенцией, воспользовавшись надуманным предлогом Турция заявила о якобы причастности Салиха Муслима, со-председателя ПДС, к взрывам в Анкаре, приведшим к гибели турецких военных и власти Турции выдали ордер на его арест. Однако, этот жест может быть направлен на ослабления влияния сторонников ПДС на тех территориях Сирии, где происходит в настоящий момент интервенция турецких войск. Поэтому когда Турция рассматривает ИГИЛ и лагеря ПРК в Кандильских горах, как угрозу своей безопасности, можно уверенно предполагать, что такой же угрозой рассматривается полунезависимая курдская «республика Рожава» на севере Сирии, с марта 2016 официально именуемая Федерацией Северной Сирии [7].

Формирование действенной коалиции против сил ИГИЛ, в которую сейчас прямо или косвенно вовлечены несколько стран, включая Россию, создает реальный очаг напряженности на границах Турции, поэтому без принципиального урегулирования курдского конфликта на этой территории невозможно ни действенное противодействие терроризму, ни нивелирование межэтнических противоречий. Важную роль в этом может сыграть Иракский Курдистан, способный заявить о себе (не без поддержки США), как о самостоятельной политической силе, взявшей на себя часть полномочий по распутыванию и урегулированию межэтнического конфликта. Только в результате отказа от взаимного насилия откроются новые возможности для курдских оппозиционеров и курдских радикалов из ПРК для ведения переговоры с правительством Турции по поводу урегулирования закоренелой курдской проблемы внутри страны.

\section{Библиография:}

1. Öcalan ve HDP'nin Hakan Fidan üzüntüsü // Новостной портал Internethaber. URL: http://www.internethaber.com/ ocalan-ve-hdpnin-hakan-fidan-uzuntusu-764318h.htm (дата обращения 10.12.2016)

2. Вертяев К.В., Иванов С.М. «Курдский национализм: история и современность» М., 2015. С. 43.

3. Selahattin Demirtaş'ın ifade metni // Hürriyet. 04.11.2016

4. Selehattin Demirtaş'tan ilk açıklama // Новостной портал www.karar.com URL: http://www.karar.com/secim-2015haberleri/selehattin-demirtastan-ilk-aciklama (дата обращения 10.12.2016)

5. Şanlıurfa Milletvekili İbrahim Ayhan: IŞİD Urfa'da karargah kurmuş // Новостной портал rasthaber.com. URL: https:// rasthaber.com/sanliurfa-milletvekili-ibrahim-ayhan-isid-urfada-karargah-kurmus/ (дата обращения 10.12.2016)

6. Rüşen Çakır. “Türkiye'nin Kürt Sorunu”. İst. 2004.

7. Курды провозгласили создание федерации на севере Сирии // Новостной портал www.lenta.ru URL: https://lenta. $\mathrm{ru} / \mathrm{news} / 2016 / 03 / 17 /$ kurds /

\section{References (transliterated):}

1. Öcalan ve HDP'nin Hakan Fidan üzüntüsü // Novostnoi portal Internethaber. URL: http://www.internethaber.com/ ocalan-ve-hdpnin-hakan-fidan-uzuntusu-764318h.htm (data obrashcheniya 10.12.2016)

2. Vertyaev K.V., Ivanov S.M. «Kurdskii natsionalizm: istoriya i sovremennost’» M., 2015. S. 43.

3. Selahattin Demirtaş'ın ifade metni // Hürriyet. 04.11.2016

4. Selehattin Demirtaş'tan ilk açılama // Novostnoi portal www.karar.com URL: http://www.karar.com/secim-2015haberleri/selehattin-demirtastan-ilk-aciklama (data obrashcheniya 10.12.2016)

5. Şanlıurfa Milletvekili İbrahim Ayhan: IŞiD Urfa'da karargah kurmuş // Novostnoi portal rasthaber.com. URL: https:// rasthaber.com/sanliurfa-milletvekili-ibrahim-ayhan-isid-urfada-karargah-kurmus/ (data obrashcheniya 10.12.2016)

6. Rüşen Çakır. “Türkiye'nin Kürt Sorunu”. İst. 2004.

7. Kurdy provozglasili sozdanie federatsii na severe Sirii // Novostnoi portal www.lenta.ru URL: https://lenta.ru/ news/2016/03/17/kurds/ 